\title{
Bringing NASA Technology Down to Earth
}

\author{
Daniel P. Lockney \\ National Aeronautics and Space Administration \\ 300 E Street, SW \\ Headquarters \\ Washington, DC 20546 \\ 202-358-2037 \\ daniel.p.lockney@nasa.gov
}

\author{
Terry L. Taylor \\ National Aeronautics and Space Administration \\ Marshall Space Flight Center \\ Huntsville, AL 35812 \\ 256-544-5916 \\ terry.taylor@nasa.gov
}

\begin{abstract}
Whether putting rovers on Mars or sustaining life in extreme conditions, NASA develops technologies to solve some of the most difficult challenges ever faced. Through its Technology Transfer Program, the agency makes the innovations behind space exploration available to industry, academia, and the general public. This paper describes the primary mechanisms through which NASA disseminates technology to solve real-life problems; illustrates recent program accomplishments; and provides examples of spinoff success stories currently impacting everyday life.
\end{abstract}

\section{Table of Contents}

1. INTRODUCTION 1

2. Patent Licensing

3. Software RElease ............................................... 4

4. SPINOFFS ........................................................ 5

5. SumMary ..................................................... 7

RERENCES ........................................................ 7

BIOGRAPHIES ..........................................................8 8

\section{INTRODUCTION}

It is one of NASA's missions to ensure that the technologies it creates for aeronautics and space exploration are turned into new products and services that benefit the lives of ordinary Americans and the U.S. economy. Through the congressionally mandated process of technology transfer, NASA maximizes the nation's investment in the agency's cutting-edge research and development. [1]

\section{Patent Licensing}

Patent licensing is a primary component of technology transfer at NASA. NASA-developed technologies can serve as the foundations of new commercial products, fuel the growth of an entire product line, or even be used to launch a new company.

The agency's patent portfolio, which can be found at technology.nasa.gov, includes more than 1,400 active patents. The portfolio is divided into fifteen categories: aeronautics, communications, electrical/electronics, environment, health/medicine and biotechnology, IT and software, instrumentation, manufacturing, materials and coatings, mechanical and fluid systems, optics, power generation and storage, propulsion, robotics/automation and control, and sensors.

All completed license applications are thoroughly reviewed, and each license agreement is custom-tailored. Amounts and dates of royalty payments, field(s) of use, geographic locations for manufacturing and product sales are negotiated between designated company points of contact and a NASA license manager.

A potential applicant or a prospective licensee may request a visit to a NASA center to observe a technology demonstration, talk with inventors in person, discuss terms, and/or participate in a license signing ceremony. Occasionally, the license applicant or interested party may be asked to sign a non-disclosure agreement before NASA shares detailed technical information about an invention if that information has not been made available to the public. All of these activities can be discussed with the requisite license manager at the appropriate time in the process.

Various types of license agreements are available. Nonexclusive agreements are the most commonly sought commercial licenses. Nonexclusive licenses can be granted to more than one company. An exclusive or partially exclusive commercial license gives a company exclusive or a limited exclusive access to NASA inventions. Exclusivity may be limited to a specific market application, field of use, or geographic region, or to a fixed period of time (e.g., five years), after which the agreement converts to a nonexclusive license. An evaluation license allows a company to internally evaluate inventions for a short period.

NASA has recently streamlined its licensing process and broadened the scope of the program. Because of these changes and others, executed license agreements have increased dramatically. Some of these improvements are described below. 


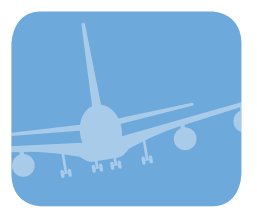

Aeronautics

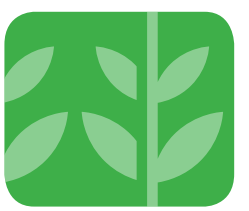

Environment

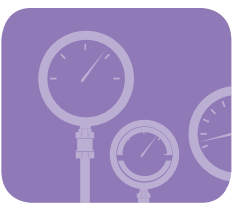

Instrumentation

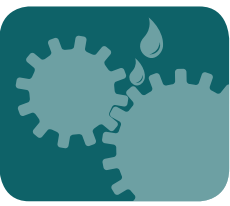

Mechanical and Fluid Systems

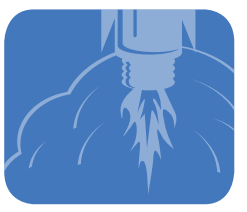

Propulsion

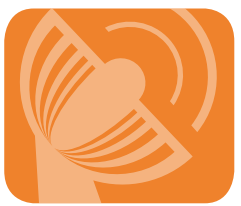

Communications

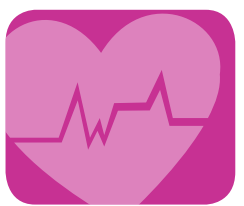

Health, Medicine,

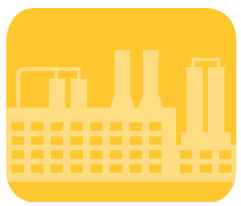

Manufacturing

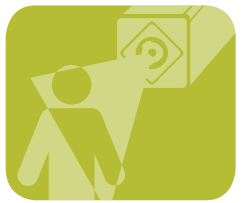

Optics

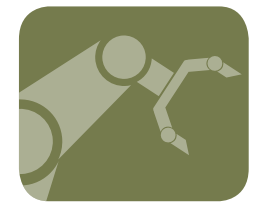

Robotics, Automation and Control and Biotechnology

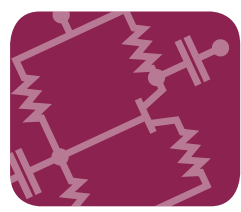

Electrical/

Electronics

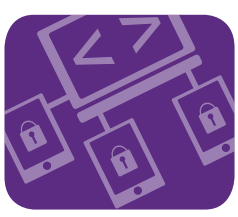

IT

and Software

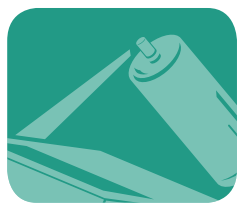

Materials and Coatings

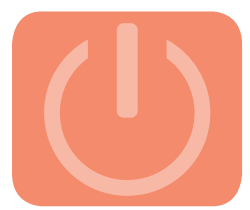

Power Generation and Storage

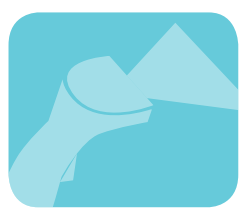

Sensors
NASA patent offerings cover a wide variety of technical applications.

\section{Automated Technology Licensing Application System (ATLAS)}

Licensing NASA patents is not new, but the license application process for a NASA patent is. Actually, it's new and better. ATLAS provides perspective licensees a centralized online tool for applying for any available NASA innovation, agency-wide.

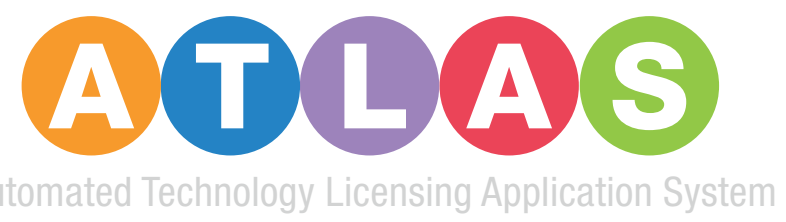

In interview style, ATLAS gathers all required information from perspective licensees on their company, their goals, and their projected target market(s). It eliminates any guessing. Email notifications keep all parties apprised of application status and any required actions.

ATLAS standardizes the patent license application procedure across all 10 NASA centers and eliminates most manual processing. Potential license agreements are routed electronically and automatically for the appropriate approvals and signatures.

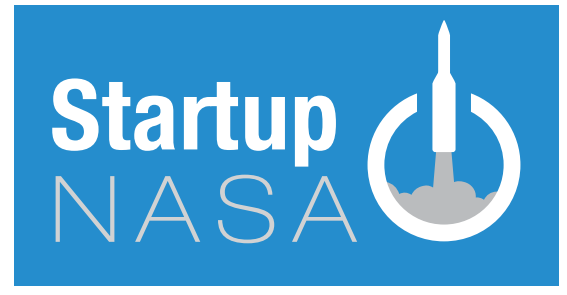

\section{Startup NASA}

By offering a license with no up-front costs, the Startup NASA initiative helps address two of the biggest challenges faced by new companies: raising capital and security intellectual property rights. NASA innovators and facilities can be available to lend additional support.

Certain rules do apply:

- This offer is open only to companies formed with the express intent of commercializing a licensed NASA technology.

- NASA waives the initial licensing fees, and there are no minimum fees for the first three years.

- Once the company starts selling a product, NASA will collect a standard net royalty fee. This money goes first to the inventor and then to maintaining the agency's technology transfer activities and technology advancement.

- This initiative applies only to non-exclusive licenses, which means other companies may apply for similar rights to use the technology for commercial purposes. However, NASA will consider further exclusivity if the startup wishes to negotiate.

- Companies entering into these licenses are bound by all requirements in federal licensing statutes and NASA policies, including development of a commercialization plan and reporting on efforts to achieve practical application.

- While NASA does license to foreign entities, this startup agreement is only available to companies in the United States.

\section{Patent Gift}

To stimulate the innovation economy, NASA has put a portion of its patent portfolio in the public domain. These technologies do not require a license agreement, and anyone may freely pursue independent product development immediately without the need to contact NASA in any way. 
The High-Strength, Wear-Resistant Aluminum Alloy:

A Patent License Success Story

The High-Strength, Wear-Resistant Aluminum Alloy is an excellent example of a NASA patent success story. The agency began work on the innovation (also known as MSFC-398) as a result of the Partnership for Next-Generation Vehicles (PNGV), a collaborative effort through which 20 federal laboratories and more than 350 universities, small businesses, and suppliers worked together to develop technologies to improve fuel efficiency and reduce emissions.

When PNGV funding ended, NASA continued to fine-tune the alloy. Today's MSFC-398 offers the higher strength at high temperatures that has led to it being an integral component of very successful commercial products that are having a positive impact on the environment and helping to save lives.

Delivering higher wear resistance, higher surface hardness, and greater stability at elevated temperatures compared to other aluminum alloys, the technology can be produced at less than a $\$ 1$ per pound. It is enabling manufacturers to make optimized, lighter weight engines that produce more horsepower and emit fewer pollutants.

Utilizing the NASA innovation for outboard marine engine applications, Bombardier Recreational Products (BRP) first introduced pistons fabricated with MSFC-398 in 2003 in its Evinrude E-TEC ${ }^{\text {TM }}$ engines. The E-TEC ${ }^{\text {TM }}$ line offers a novel design that combines features that have never been offered together in a single engine: it meets three-star emissions requirements for the California Air Resources Board, operates with no scheduled dealer maintenance for three years, and uses approximately $20 \%$ less oil than conventional direct-injection engines. The E-TECTM has been given the highest possible customer satisfaction rating in a study by J.D. Power and Associates and has also won a first-place Environmental Excellence in Transportation Award by the Society of Automotive Engineering. So impressed with MSFC-398's performance, BRP now uses the technology in every line of its Evinrude engines.

Another license of MSFC-398 executed with Twin City Fan is allowing the innovation to be utilized to develop much needed $\mathrm{road} / \mathrm{rail}$ tunnel safety fans. New standards dictate that these fans be able to operate at $752{ }^{\circ} \mathrm{F}$ for two hours in order to be certified for use. The reason for the high temperature requirement is because the fans must be able to operate successfully during a fire or other emergency situation.

Before selecting the NASA alloy, Twin City had only two ways to meet the new regulations that have been set. Option one was to use another aluminum alloy; the resulting fan would have been much larger. The drawback here is that a bigger fan would require more space, and even taking a single foot out of the construction of a tunnel means a dramatic cost savings.

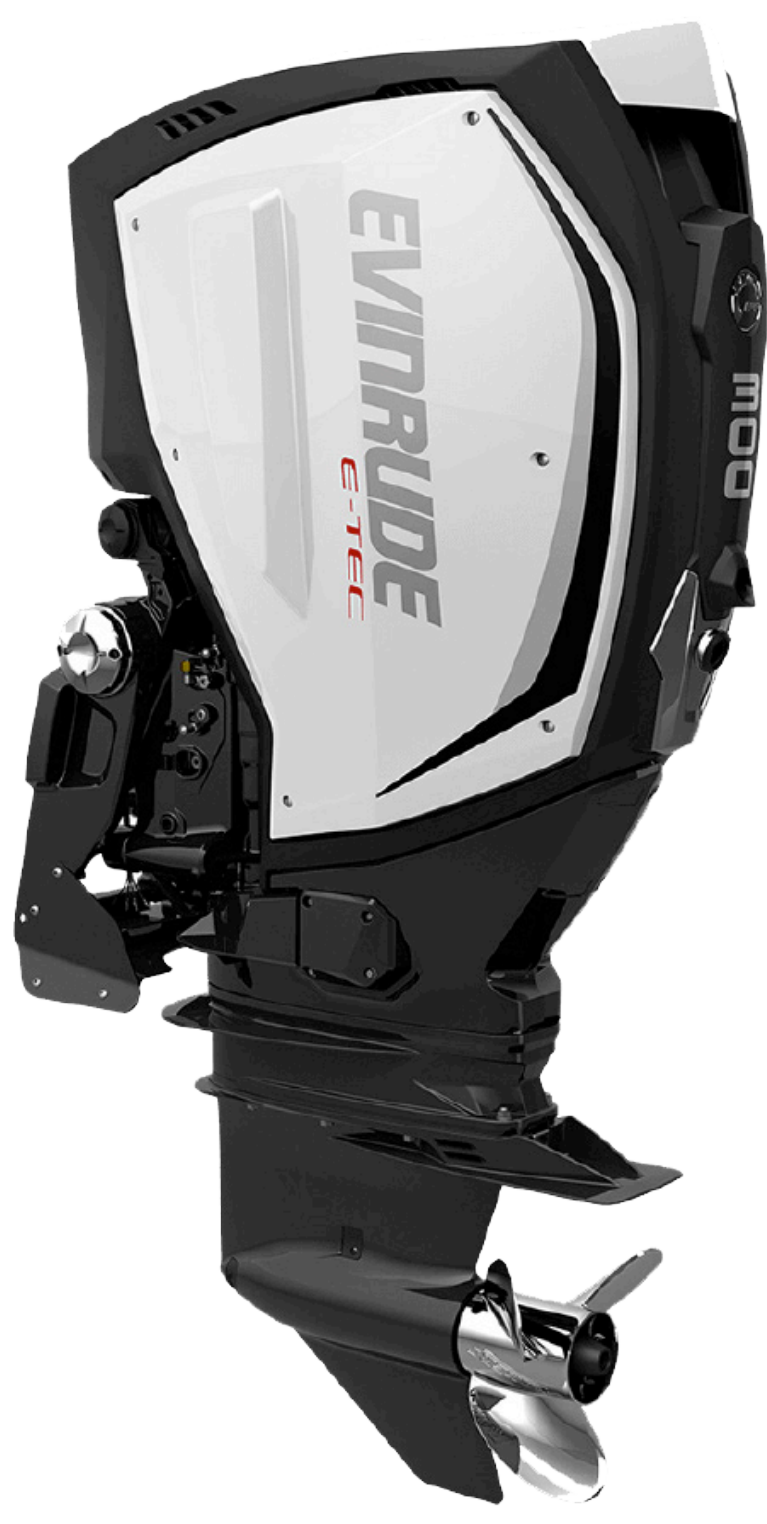

Licensing agreements for the MSFC-398 aluminum alloy exemplify the impact of successful technology transfer.

The other option was to make the fan blades out of steel, but this would have required a specialized motor to turn the fan blades since steel weighs three times more than aluminum.

The NASA technology continues to amass a variety of accolades. It has been honored with both Southeast and National Excellence in Technology Transfer Awards by the Federal Laboratory Consortium. 


\section{Software Release}

The release of NASA software to the public is another key mechanism of technology transfer at NASA. These are the actual codes NASA engineers have developed to do their work. Each code is available at no cost.

Software has always been at the core of NASA's mission successes, and NASA makes a concerted effort to always track and utilize its software tools to their full potential. A code developed for a specific need may have application to a variety of other NASA projects or programs, or it might be of interest to the Department of Defense, other government agencies, commercial space companies, private industry, or the general public.

All software developed at NASA that is made available to others goes through an official software release process, which is led by the Software Release Authority (SRA) at each center. Before it can be released, all software undergoes an export control review, an intellectual property review, and a commercialization assessment to determine if it meets NASA's policies and guidelines.

The NASA Software Catalog and Other Recent Developments

In the last 6 years, NASA has re-energized its efforts in the area of software release. The collection and compilation of hundreds of software codes from all ten NASA centers to build a comprehensive software catalog and repository can be considered an excellent example of this.

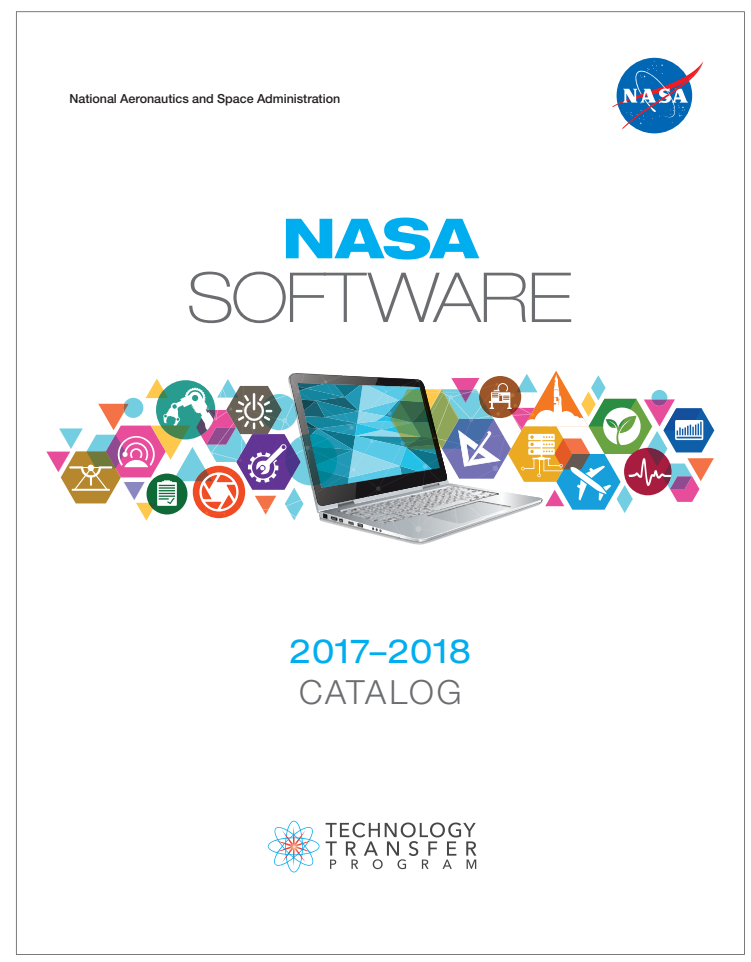

The NASA Software Catalog includes many of the tools the agency uses to explore space and broaden humankind's understanding of the universe.

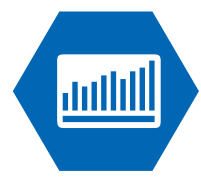

Business Systems and Project Management

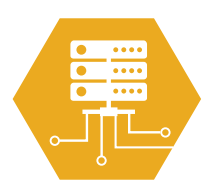

Data Servers Processing and Handling

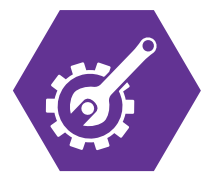

Materials and Processes

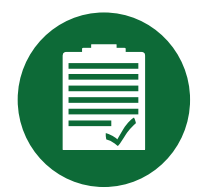

System Testing

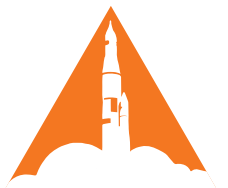

Propulsion

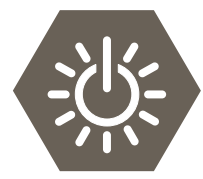

Electronics and Electrical Power

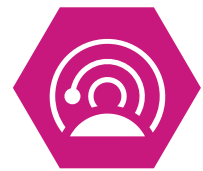

Operations

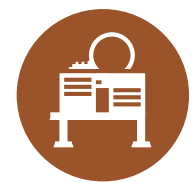

Environmental Science

Earth - Air • Space - Exoplanet

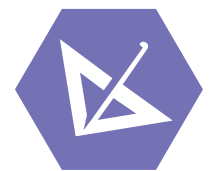

Design and Integration Tools

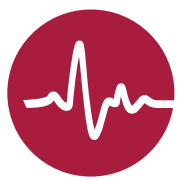

Crew and Life Support

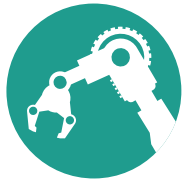

Autonomous Systems

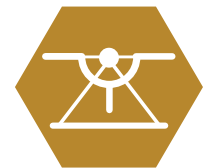

Vehicle Management Space $\cdot$ Air $\cdot$ Ground

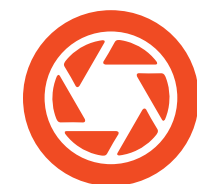

Data and Image Processing

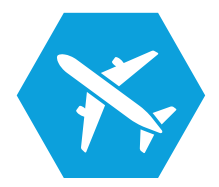

Aeronautics

Structures and Mechanisms

NASA software offerings cover a wide variety of technical applications. 
The NASA Software Catalog consolidates the agency's best solutions to a wide array of complex problems. When it was initially released in 2014, it became the first tool of its kind from a federal agency. At the time, more than 50 media outlets highlighted it and its importance, including NPR, Gizmodo, and Newsweek. The White House Office of Science and Technology Policy hailed the publication as a very worthy accomplishment. The fourth edition of the catalog is currently in the works.

For the 2017 version of the catalog, NASA launched an extensive social media campaign, utilizing the agency's Twitter, Facebook, Instagram, Snapchat, LinkedIn, Tumblr, and other accounts to reach millions of potential users. As a result, the number of Software Usage Agreements has increased dramatically, almost doubling between FY16 and FY17. The campaign resulted in the creation of 22,551 new user accounts, 207,628 catalog downloads, and 161,202 YouTube views.

In October of 2016, NASA introduced a new online Software Release System (SRS). The SRS provides developers with a single platform to ready their software for release to the users who need it; employs a simple online questionnaire to replace multiple forms used previously; and allows software packages to be reviewed concurrently by all necessary reviewers.

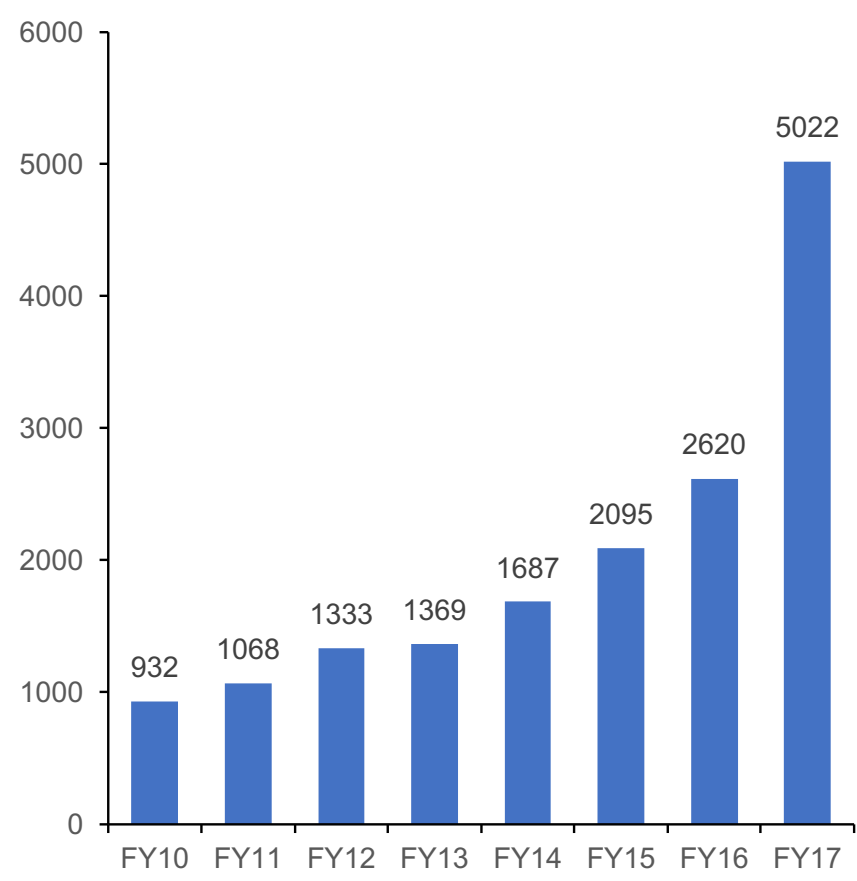

The number of Software Usage Agreements has climbed dramatically since 2010 .

\section{SPINOFFS}

There is probably more "space" in everyone's life than he imagines. NASA's Spinoff magazine is an annual publication that has been written and released for each of the last 40 years. Its pages have showcased more than 2,000 products, tools, processes, and improvements with their origins in America's space program that have found new life outside of NASA. Examples of technologies featured in the 2017 edition of Spinoff are profiled below.

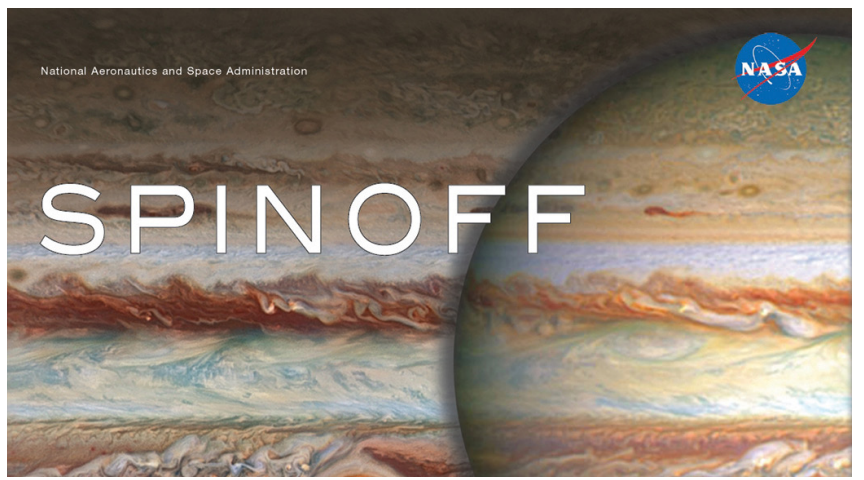

\section{Crash Test Cameras}

Under a NASA contract, Integrated Design Technologies developed a rugged, compact, high-speed video camera with ultra-fast solid-state memory to record parachute deployment during a test flight of the Orion spacecraft. The camera captured 1,000 frames per second, backing up 12 gigabits of data per second as it filmed. Today, a commercialized version of the technology is being used in automobile crash-testing and in filming slow-motion sequences for television. [2]

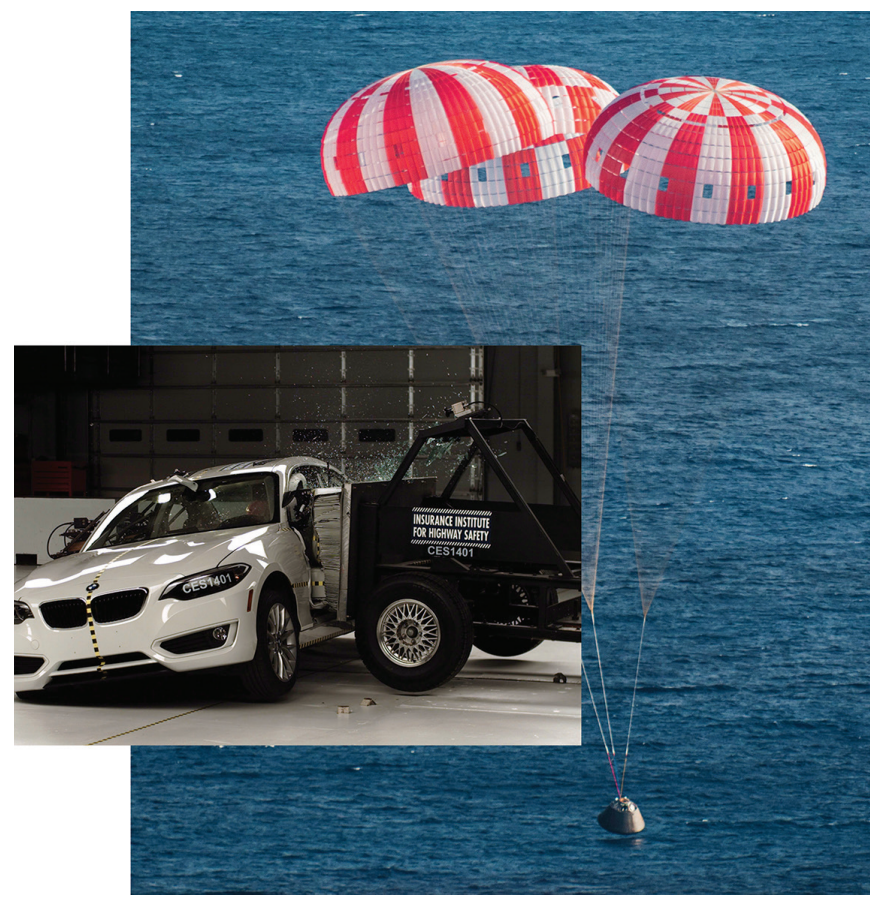

Orion video requirement advances high-speed, compact cameras. 


\section{Self-Driving Tractors}

Beginning in the 1990s, NASA researchers developed software to correct for Global Positioning Sensor (GPS) signal errors, enabling location accuracy to within inches. John Deere acquired the technology and used it to develop the world's first widely used self-driving farm equipment. Currently, as much as 70 percent of farmland in North America, 50 percent in Europe and South America, and 90 percent in Australia is cultivated by self-driving tractors, many of which still rely on technology originally developed at NASA. [3]

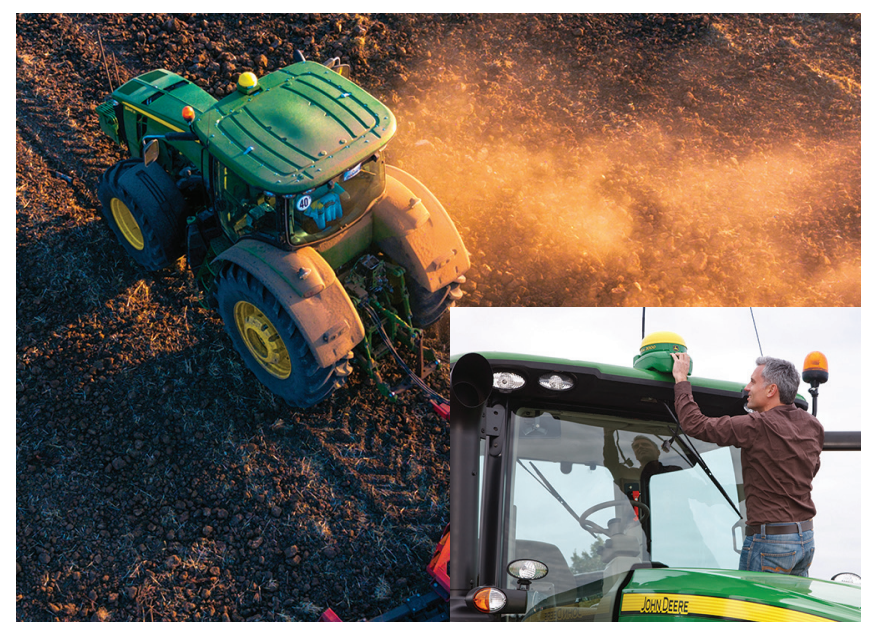

Sensor correction technology lets tractors drive themselves.

\section{Fluid Damper Technology}

During its test launch, the Ares-1X test rocket experienced unexpected resonant vibrations that could have harmed future astronaut crews. To solve the problem, NASA engineers invented a new kind of dampening device that uses the weight of a liquid mass (e.g., rocket fuel) to counteract resonance. The innovation has significant potential for broad application in any skyscraper, bridge, stadium, or other structure prone to vibration. Its first commercial use came in the B2 Building, the world's largest modular building, which is situated next to Barclay's Center in Brooklyn, New York. [4]

\section{Mini Heat Pipes}

Over the course of more that 40 Small Business Innovation Research (SBIR) contracts since the 1980s, many with Glenn Research Center, NASA has helped Pennsylvania-based Thermacore advance the technology of heat pipes, a tool used to move heat so it can dissipate safely. In the last decade, the NASA-improved heat pipes have been adapted to medical uses, including bipolar forceps utilized in brain surgery. [5]

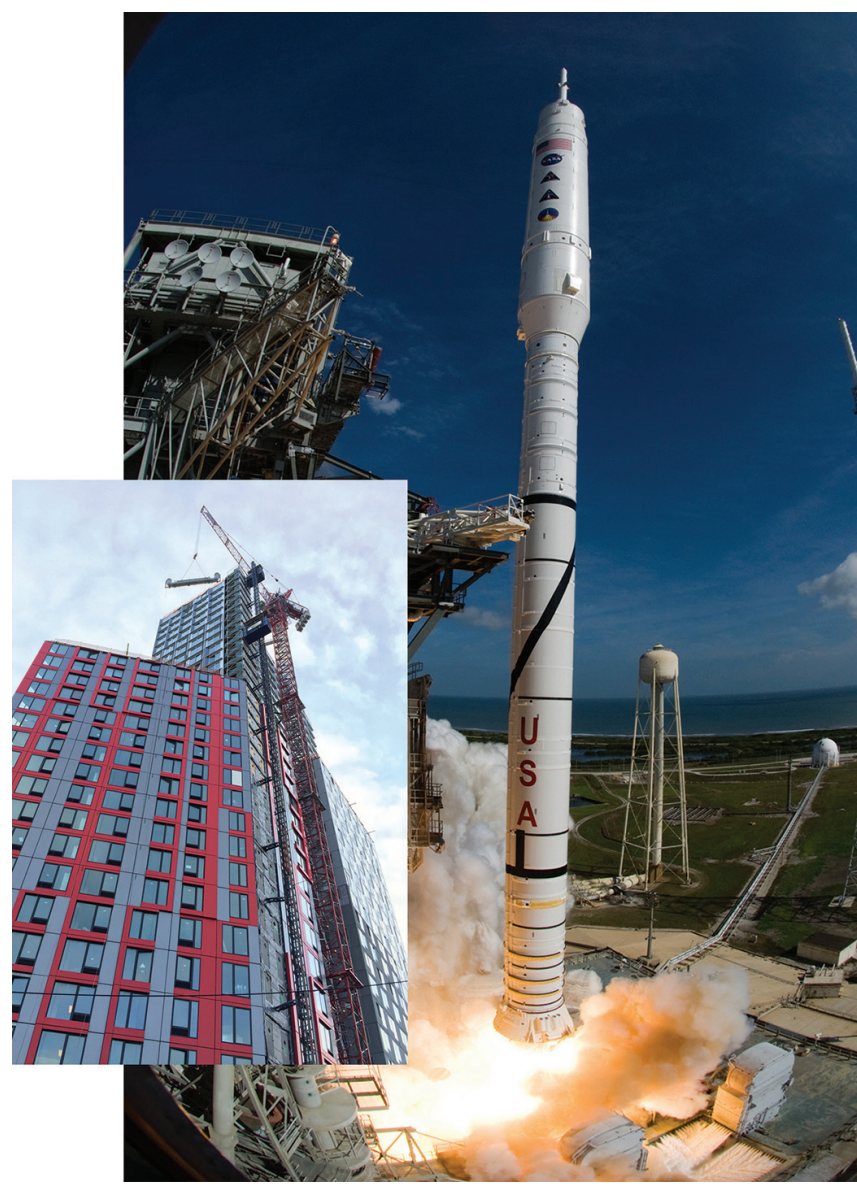

Rocket technology counteracts vibrations.

Phase-Change Materials (PCMs)

One method Johnson Space Center investigated for managing heat inside a spacesuit was the use of phase-change materials. Like ice cubes in a drink, PCMs absorb heat as they change from solid to liquid, and, if exposed to colder temperatures, they release that heat as they refreeze. An SBIR contract led to the creation of fabrics incorporating PCMs, most recently commercialized by San Francisco-based Embrace Innovations in wraps and blankets that help keep babies at an optimal temperature. [6]

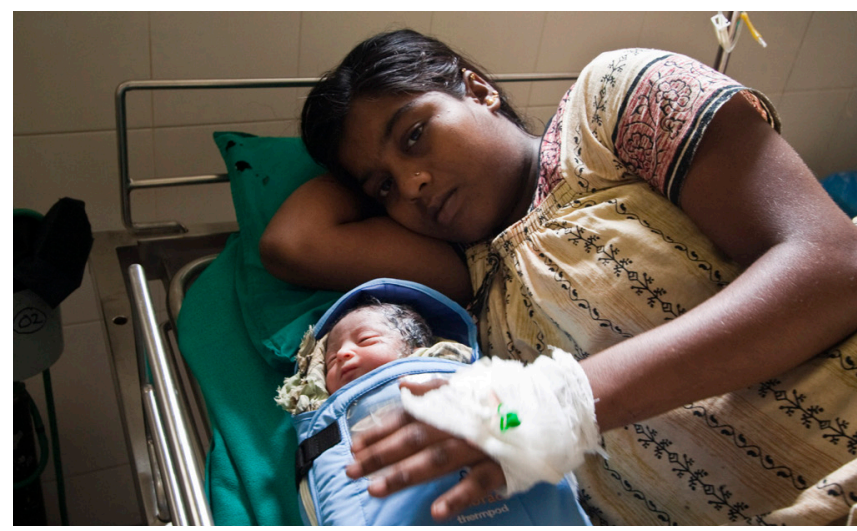

Temperature-regulating fabrics help keep babies comfortable. 


\section{Phone Camera Sensors}

In the 1990s, Jet Propulsion Laboratory engineer Eric Fossum invented what would become NASA's most ubiquitous spinoff - digital image sensors based on complementary metal oxide semiconductors (CMOS). These were significantly smaller and more efficient than the charge-coupled-device imagers of the day and enabled tiny, battery-friendly cell phone cameras and high-definition video cameras, such as those offered by GoPro, a San Mateo, California-based company. [7]

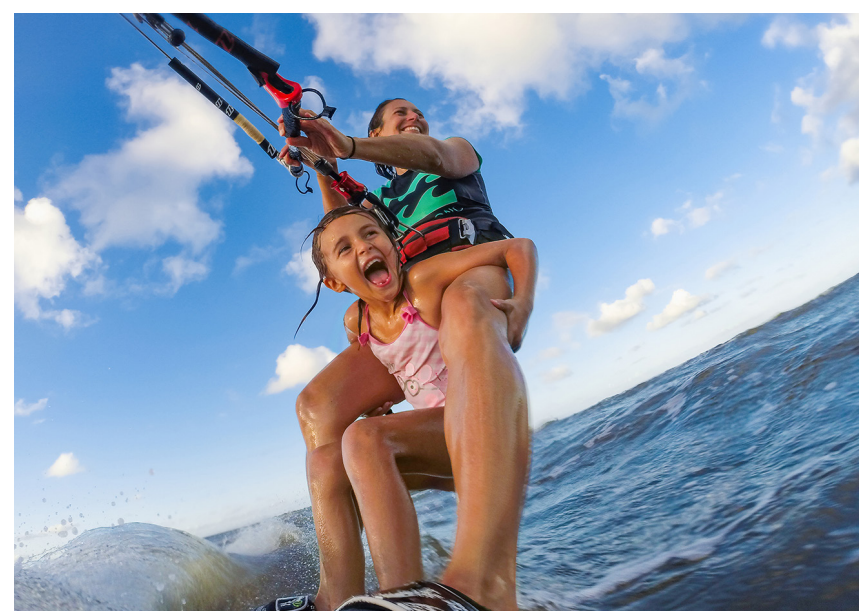

NASA-based semiconductor sensors enable phone cameras.

\section{Hearing Aid batteries}

In its early days, NASA spent much effort developing rechargeable silver-zinc batteries, as the pairing of silver and zinc offers a higher power-to-weight ratio than any other coupling. Significant advances in the durability of the batteries were made at Glenn Research Center, which Zpower of Camarillo, California, used as part of its starting point, undertaking years of additional development before releasing its rechargeable hearing aid batteries, the first that can last all day on a single charge. [8]

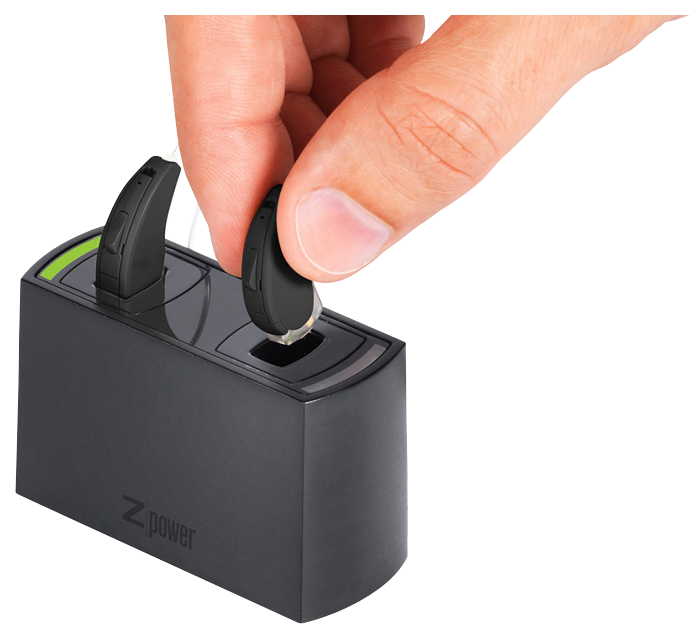

Rechargeable hearing aid batteries draw from NASA research.

\section{Summary}

Innovation is NASA's specialty, and through the patent licensing program and software release, an average American can benefit directly from the creativity and expertise of thousands of civil service and contractor scientists and engineers. Advances with their origins in the space program save and improve lives, create jobs, and maximize taxpayer investment in the agency.

\section{REFERENCES}

[1] Partial listing of external and internal regulations governing NASA's technology transfer responsibilities:

Stevenson-Wydler Technology Innovation Act of 1980, 15 U.S.C. $\S 3710$ et seq., as amended

Bayh-Dole Act (P.L. 96-517), 35 U.S.C. § 200 et seq., as amended

National Aeronautics and Space Act 51 U.S.C. § 20113(a).

Commercial Technology Transfer Program 51 U.S.C. § 50116.

Rights to Inventions Made by Nonprofit Organizations and Small Business Firms Under Government Grants, Contracts, and Cooperative Agreements, 37 CFR Part 401.

Licensing of Government-Owned Inventions, 37 CFR Part 404.

"NASA Technology Transfer Requirements," NASA Procedural Requirement 7500.2.

"Release of NASA Software," NASA Procedural Requirement 2210.1C.

"Authority to Enter into License Agreements and Implementation of Licensing Authority," NASA Procedural Requirement 22090.6.

[2] More information can be found in Spinoff 2017, p. 68.

[3] More information can be found in Spinoff 2017, p. 110.

[4] More information can be found in Spinoff 2017, p. 72.

[5] More information can be found in Spinoff 2017, p. 38.

[6] More information can be found in Spinoff 2017, p. 48.

[7] More information can be found in Spinoff 2017, p. 86.

[8] More information can be found in Spinoff 2017, p. 96. 


\section{BIOGRAPHIES}

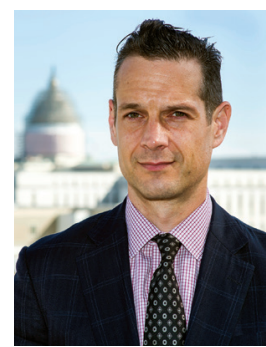

Daniel P. Lockney is the Technology Transfer Program Executive at NASA Headquarters in Washington DC, responsible for agency-level management of NASA intellectual property and the transfer of NASA technology to promote the commercialization and public availability of federally owned inventions to benefit the national economy and the U.S. public. Lockney oversees policy, strategy, resources, and direction for the agency's technology commercialization efforts.

Lockney studied American Literature at the University of Maryland, Baltimore County and creative writing at Johns Hopkins University. He started his NASA career as a contractor in 2004, converting to civil service in 2010. He lives in University Park, Maryland, with his wife and two space pups, Astro and Cosmo.

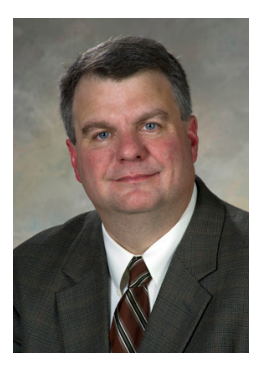

Terry L. Taylor is the manager of the Technology Transfer Office at NASA's Marshall Space Flight Center (MSFC), which is responsible for a broad range of propulsion, scientific, and space transportation activities contributing to the nation's space program.

Taylor began his government career as electronics engineer at the U.S. Army Space and Missile Defense Command in Huntsville, Alabama, joining NASA in 2000. Before his current post in the Technology Transfer Program, he served as the project manager of the Ares I Launch Vehicle integrated design and analysis team, was deputy of the Constellation development planning team, and worked as a project engineer on the $X$-37 reusable space plane program.

A native of Vicksburg, Mississippi, Taylor earned both bachelor's and master's degrees in aerospace engineering from Mississippi State University. 